\title{
Do Time Travelers Suffer from Paradoxes?
}

\author{
Daisuke $\mathrm{KACHI}^{*}$
}

\begin{abstract}
In this paper I give consideration to some apparent impossibilities for the time travelers to the past. After criticizing the views of D. Lewis and K. Vihvelin, I will show in what sense they are really impossible.
\end{abstract}

Even if time travelers go to the past, there are things that they seem unable to do:

(1) Changing the Past

(Time travelers would never make what has not happened happen or undone what has happened.)

(2) Autofanticide

(Time travelers would never kill their younger selves or their ancestors.)

(3) Autoparenthood

(Time travelers would never become their parents or their ancestors.)

Are these really impossible for time travelers? If so, are the reasons for their impossibilities same for all these three things?

Autofanticide is a special case of changing the past. So David Lewis did not distinguish them in considering their possibilities. According to him, apparent paradoxes result from the equivocation of "can". He says: "What we can do, relative to one set of facts, we cannot do, relative to another, more inclusive, set."(1) Our changing the past, including autofanticide, is possible relative to all the facts of the sorts that we would ordinarily count as relevant in deciding what someone can do. But it is not compossible with another, larger set of facts, including, for instance, the fact that someone is alive in 2006. Once we realize this equivocation of "can", the apparent paradoxes will dissolve.

Lewis says that supposing to change the past is to make a counterfactual supposition and hold all else as close to fixed as you consistently can. The difference between supposing to kill my ancestors in the past and to kill strangers of mine in the past lies only in the easiness of fixing the facts evading contradictions.

* Saitama University 
For the former we would have to suppose some extraordinary things to avoid contradictions, for instance, the hypothesis that the killed ancestors miraculously resurrected. Compared with that, we could more easily suppose to kill strangers and avoid contradictions. But that's all of the difference.

Vihvelin agrees with Lewis in taking the possibility of changing the past as a matter of making a counterfactual supposition. However, she did not insist that autofanticide is just a special case which could be dealt with in the same way as other cases of changing the past. According to her, autofanticide is impossible because the following counterfactual proposition is false: "If a time traveler had tried to kill her younger self (many times), she might have succeeded". The reason is that its truth implies the denial of the natural law that a person's adulthood is caused by her childhood.(2) So it does not satisfy the requirement of counterfactual supposition to keep all else as close to fixed as you consistently can. By contrast, she did not believe that the proposition "If a time traveler had tried to kill one of her strangers (many times), she might have succeeded." is evidently false. For its truth does not necessarily contradict natural laws.

Here I would not try to decide which is right. Rather I would point out that both of them somewhat beg the question in taking the paradoxes as a matter of counterfactual supposition. To argue about counterfactual possibility of changing the past presupposes at least its metaphysical possibility. They seem to agree in thinking that if anything is logically possible, all the rest to consider is its causal or nomological possibility. In fact Vihvelin says: "The impossibility I am arguing for is neither anayltic nor logical; it's nomological."'(3) They just disagree in deciding how far we have to fix causal factors or natural laws to make a counterfactual supposition.

I believe that the possibility of three types of action, shown at the beginning of this paper, does not depend on what causal factors and natural laws happen to hold in the actual world. Indeed I believe that they are all impossible for the same metaphysical reason. Below I try to make that reason explicit.

Firstly I adopt the thesis that the present and the past is real but that the future is not. Then I reformulate this thesis as the following premise :

Premise-A For any subject $x$ and any two events $e$ and $f$, if $x$ experiences $f$ after $x$ experiences $e$, then $f$ is not real at the moment when $x$ experiences $e$. On the other hand, $e$ is real at the moment when $x$ experiences $f$.

This formulation finds the source of the ontological asymmetry between the past and the future in the ontological asymmetry that lies in the history of a subject. Excepting the boundary moments of its birth and death, the history of a subject always consists of two parts: the real and determinate part from its birth to the 
present and the unreal and indeterminate part from the present to its death. I believe that our intuition of asymmetry in time originates from this fundamental asymmetry in our life.

If you accept Premise-A, you can prove that you cannot go to the moments when your autofanticide may occur. For it follows from the premise that a subject cannot have any contact with her younger self. For example, it is impossible that Mary, who was born in 1960 and is alive in 2000, travels to the year 1980 and meets her younger self, since it follows that her departure (in 2000) for the past is both real and not real in 1980. It is real because, in view of her time travel, she encountered her younger self (in 1980) after the departure (in 2000) for the past. At the same time, it is not real because, in view of her lifetime until 2000, she began her time travel (in 2000) after encountering her older self (in 1980). (figure 1) Here is the contradiction.

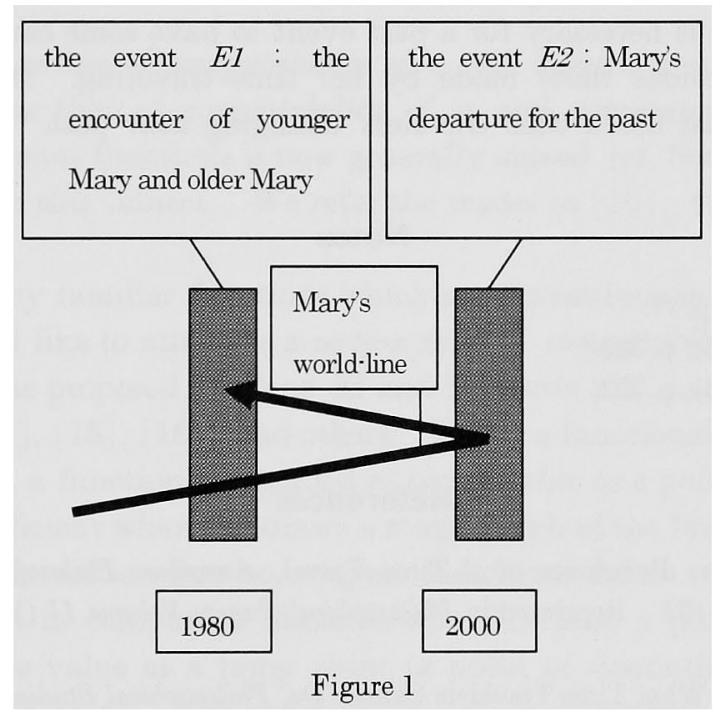

It is to be noted that the precise meanings of the words 'real' and 'moment' used in Premise-A make no difference to the proof. The word 'real' is just required to have a certain univocal sense that keeps Premise-A acceptable. As for the word 'moment', since only the two successive events along Mary's world-line are concerned, the relativity of simultaneity with each event does not matter.

However, Premise-A has limitations. It is just concerned with a single subject's experiences. So it cannot block, for instance, a time traveler's murder of his grandfather. Moreover, since it describes a subject of experiences, it cannot exclude the possibility of changing the past by something that cannot have experiences, say, a stone, a table etc. So I generalize Premise-A to Premise- $\mathrm{A}^{\prime}$ : 
Premise-A $\mathbf{A}^{\prime} \quad$ For any substance-chain $x$ and any two events $e$ and $f$, if $f$ occurs to $x$ after $e$ occurs to $x$ along its world-line, then $f$ is not real at the moment when $e$ occurs to $x$. On the other hand, $e$ is real at the moment when $f$ occurs to $x$.

By 'substance-chain' I mean a collection of substances that are linearly ordered by a sort of parenthood relation that can be also applied to non-living things, for example, the relation between a watch and its parts. A substance-chain serves as a dummy for a substance. By this generalization, autofanticide and autoparenthood immediately become impossible, since both presuppose that a substance can come into contact with its earlier itself or one of its ancestors.

As for changing the past, its impossibility is not so evident. However, if there are any substance-chains that lie between the substances participated in a past event and a time traveler, her interfering with that event will be also prevented. I believe that this condition is necessary for a past event to have some causal connections to a time traveler besides those made by her time-traveling. If that is true, my solution will at least block time travelers' changing their past.

\section{Notes}

(1) Lewis (1986), p. 77.

(2) Vihvelin (1996), p. 329

(3) Vihvelin (1996), p. 323.

\section{References}

(1) Lewis, D. The Paradoxes of a Time Travel, American Philosophical Quarterly 13 (1976), pp.145-152. Reprinted in Philosophical Papers Volume II (1986), Lewis, D., pp. 67-80.

(2) Vihvelin, K. What Time Travelers Cannot Do, Philosophical Studies 81, 315-330, 1996. 